\title{
Innovation of Bazaar Harper's BAZAAR in the New Media Era: Fan Economic Application
}

\author{
Danran Lyu ${ }^{1, a, *, \dagger}$, Jiajie Wang ${ }^{1, b, *, \dagger}$
}

\author{
${ }^{1}$ Rutgers University, New Brunswick, NJ, USA \\ ${ }^{*}$ Corresponding author. Email: ${ }^{a}$ dl886@scarletmail.rutgers.edu, ${ }^{b} j w 1196 @$ scarletmail.rutgers.edu \\ These authors contributed equally.
}

\begin{abstract}
This article explores the localization efforts made by the famous American fashion magazine Harper's BAZAAR in mainland China, focuses on BAZAAR star electronic magazine, and discusses its application to the fan economy. This article will start with the localization trend, the achievements of the fan economy for Harper's BAZAAR, the comparison between physical paper publications and electronic publications, and the specific online and offline operations of electronic publications on the fan economy. It reflects that the BAZAAR star electronic magazine in mainland China can produce hot-selling localized content and save its own declining paper-magazine media. This article will use the communication theory to demonstrate the fan economy and the connection between Harper's BAZAAR and its buyers to prove why Harper's BAZAAR can use the fan economy to take a new path exclusively for this magazine.
\end{abstract}

Keywords: e-magazine, fan economy, Harper's BAZAAR, new media era

\section{INTRODUCTION}

As an established fashion magazine, Harper's BAZAAR(Chinese) has been exploring new developments and opportunities for many years. The origin company of Harper's BAZAAR(Chinese) is Harper's BAZAAR. This well-known American fashion magazine has been following its high-end path for more than 140 years, maintaining a unique sense of fashion smell and acumen in the magazine, providing authoritative fashion information and high-end elegance for fashion women of all ages. In BAZAAR's slogan, they believe in the maxim of "Make fashionable women more successful, make successful women more stylish" and have perfectly embodied this declaration over the years of their history. Based on the Chinese domestic fashion industry's vigorous development, the BAZAAR Group started to notice the Asia-Pacific market as a big new one. They noted that the AsiaPacific market is a region with the potential for rapid growth. Later then, Harper's BAZAAR officially opened up the business of cooperation with mainland magazines. In 2002, the Fashion Group introduced the United States Hearst Publishing Group's "Harper's BAZAAR". Then with the origin "China Fashion" magazine, the Fashion Group localize and integrate BAZAAR to introduce this new magazine into the China mainland magazine industry. After three years of copyright cooperation, "China
Fashion" finally changed its name to our now familiar Harper's BAZAAR(Chinese). The new Harper's BAZAAR(Chinese) promoted the formation of China's fashion industry, introducing a new development path for China's modeling industry, clothing industry, fashion photography, modeling industry, etc. It opened up a new way to internationalization and marketization. What's more, this magazine began to serve the elite women in Chinese society with a high profile.

At the same time, since the birth of Harper's BAZAAR (Chinese) depends on the cooperation and efforts both the Chinese mainland and the United States BAZAAR put on, Harper's BAZAAR (Chinese) gradually opened a road of internationalization as well. Today, as an international magazine, Harper's BAZAAR (Chinese) also contains the latest fashion news and other elements of fashion.

On the transformation way of BAZAAR, they are also exploring some new concepts to incorporate into their magazines. Among them, the most widely used of which is the concept of an economy. When we localize the concept of fan economy, it often refers to the structure of the relationship between celebrities and their followers on the business income-generating behaviour. It is a kind of business operating model by improving user stickiness 
and word-of-mouth marketing to obtain economic benefits and social benefits [1]. In this model, the fan economy has produced its peculiarity as low operating costs, high customer stickiness, and a large impact on society [2]. And Harper's BAZAAR (Chinese) is searching for new development by using this feature in the new electronic magazine they founded.

\section{INNOVATION OF BAZAAR MAGAZINE IN THE NEW MEDIA ERA}

In today's world, the paper media is fading, which expanding a new path for fashionistas is necessary for any magazine to survive. As modern, fast-paced electronic devices account for most of the market, Harper's BAZAAR (Chinese) has to change a lot to make more in line with market adjustments. They began to focus on the choice of electronic publications. [4] For Harper's BAZAAR (Chinese), it was a "breakthrough" of traditional fashion media. They break the concepts inherent in the fashion industry and expanding the audience, content, and form, from traditional paper magazines to creating electronic magazines, ushering in the mini BAZAAR era [5]. In the transformation of the electronic magazine, Harper's BAZAAR (Chinese) took a step to change the form of the main magazine and innovatively put forward the concept of BAZAAR star electronic magazine implemented it.

Nowadays, more and more young people are willing to invest a lot of time and energy to pursue celebrities. Harper's BAZAAR (Chinese) founded the BAZAAR star electronic magazine to give fans a more convenient way to access their favorite celebrity artists [5]. When Harper's BAZAAR's (Chinese) first celebrity e-magazine was released, it used the simple words of "proving your love" to encourage the fans. Meanwhile, this new electronic magazine is also creating a new model for selling content. Since then, this electronic magazine has become a great work about the era of celebrities with huge followings, which traditional media have high hopes for. The BAZAAR star has successfully transformed itself into the fan economy [6].

And this successful transformation success is inseparable from the fragmentation mass audience theory's support. In this theory, the masses are divided into different groups, and each group receiving information, understanding information has its subjective initiative [7]. In other words, when their favorite celebrities appear in electronic magazines, fans will naturally be attracted. This is exactly what Harper's BAZAAR (Chinese) wants to achieve in this electronic magazine, even if there is a gender age education level, income, and other aspects of the difference. Still, as long as Harper's BAZAAR (Chinese) can relatively accurately locate these fans, Harper's BAZAAR (Chinese) can harvest a fairly good dissemination effect. Judging from the media separation trend of the fragmentation mass audience theory, it can be divided into three categories as a whole: elite media, mass media, and professional media. In these three categories, the elite media represent the early press, during which reading newspapers is a luxury chosen by a few well-educated elites. In contrast, the mass media represent the majority of popular reading, which has high popularity to meet most people's basic needs [7]. And Harper's BAZAAR's (Chinese) electronic magazine belongs to the remaining category---- professional media, professional media in the modern society represents a new media to meet the needs of diversification. Since the BAZAAR star electronic magazine only face the current artist stars, the audience size is relatively small, which means the electronic magazine has the greatest extent to meet most requirements of this small audience.

\section{COMPARISON BETWEEN THE ELEC- TRONIC VERSION AND THE PHYSICAL VERSION}

Before comparing an electronic magazine and a physical magazine, I would like to introduce theoretical support: uses and gratifications approach. This theory is different from some past research because it starts from the dissemination of the audience. From their point of view to analyze the audience's media contact motivation and how these contacts meet the audience's needs, to learn the psychological and behavioral effects of mass communication to people. [8] From this theoretical background to analyze, the existence of electronic magazine is based on the celebrities' fans as the main body to support the future development, is to attract fans as the first goal, through the content of the artist-related interviews or personal life to meet the desire of fans to know more about their following KOLs or other huge influencers.

To meet fans' wishes better so that BAZAAR can develop electronic magazines much rapidly, the first necessary thing to do is understand how the fans' mentality is formed. From a fan's perspective, they don't have much opportunity to reach out to their favorite celebrity artists in their daily lives. Fans are more willing to subscribe to support their favorite artists when the e-magazine focuses on behind-the-scenes and fashion hard-nosed photos. BAZAAR star e-magazine, as a bridge connecting artists and fans, focuses on the expectations of fans in content and enhances the motivation of fans' subjective desires. In addition, due to the sheer size of the fan base and the inconclusively of identity, it is difficult to meet the needs of all fans at the price of physical magazines. In this case, the birth of the electronic magazine perfectly solved this problem. The price of 6 per book can be relatively easy to accept by most fans. In terms of price and content, electronic magazines can better satisfy fans who want to meet artists and understand the mentality of artists' lives.

As a new type of magazine, e-magazines have changed a lot compared to the physical magazines of the 
past, and I will use a simple chart to show the similarities and differences between e-journals and physical journals.

Table 1. Compare e-magazine and physical magazine

\begin{tabular}{|c|c|c|}
\hline & e- magazine & $\begin{array}{l}\text { Physical maga- } \\
\text { zine }\end{array}$ \\
\hline price & 6 & $20-25$ \\
\hline CONTENT & $\begin{array}{l}\text { Interviews with art- } \\
\text { ists or groups, tid- } \\
\text { bits, fashion pho- } \\
\text { tos } \\
\text { Current hot drama- } \\
\text { related artist inter- } \\
\text { views }\end{array}$ & $\begin{array}{l}\text { Gauding fash- } \\
\text { ion, fashion in- } \\
\text { formation, ad- } \\
\text { vertising, jew- } \\
\text { elry }\end{array}$ \\
\hline audience & Fans & $\begin{array}{l}\text { Loyal fans, } \\
\text { year-round sub- } \\
\text { scription groups }\end{array}$ \\
\hline $\begin{array}{l}\text { spread } \\
\text { method }\end{array}$ & Electronic & $\begin{array}{l}\text { Physical maga- } \\
\text { zine }\end{array}$ \\
\hline subscription & $\begin{array}{l}\text { Official Wechat } \\
\text { program }\end{array}$ & $\begin{array}{l}\text { Post office sub- } \\
\text { scriptions, } \\
\text { newsstands }\end{array}$ \\
\hline $\begin{array}{l}\text { flexibility } \\
\text { (based on } \\
\text { market } \\
\text { change) }\end{array}$ & $\begin{array}{l}\text { Can temporarily } \\
\text { change the next } \\
\text { topic of the maga- } \\
\text { zine }\end{array}$ & $\begin{array}{l}\text { Hard to change } \\
\text { pre-printed or } \\
\text { scheduled } \\
\text { printed contents }\end{array}$ \\
\hline
\end{tabular}

As seen from this simple chart above, the preference for content has changed dramatically due to the obvious differences in audiences between electronic and physical magazines. Electronic magazines pay more attention to the wishes of the relevant celebrities' fans. They use many efforts on what fans want to see, which means this kind of magazine sticks closer to the fan's ideas. While the physical magazine, as always, upholds the principles of fashion, they pay more attention to fashion topics and the magazine itself as a fashion magazine positioning. From the point of view of portability and subscription, electronic magazines are also more in line with the current young people's reading habits. Wechat programs, as a carrier for dissemination, not only greatly increased the convenience of communication, also save printing costs. This can lead to the result of the lower price in the electronic magazine. It is precisely because of these advantages that Harper's BAZAAR (Chinese) can attract more fans to subscribe to their electronic magazines and thus increase the number of subscriptions. Finally, the high degree of flexibility of the electronic magazine is another focus of a major change. Since publishing the electronic magazine does not need the publication number, the editors can quickly adjust their next contents according to the latest developments in the market. Among the issued magazines, The Longest Day in Chang'an and World of Honor (Gong Jun- Zhang Zhehan) are both positive examples of BAZAAR star electronic version's flexibility according to the latest market trends. Even there was little advertising before its release, The Longest Day in Chang'an electronic magazine still brought in 132,000 sales based on the heat of the play. And the magazine was even prepared before the show was broadcasted. Once the World of Honor turns to be popular, BA-
ZAAR star took the time to release the magazine and finally successfully won 346,000 subscriptions. According to the previous two examples, the flexibility of e-magazines is positive feedback on market demand compared to physical magazines, so it is much predictable that the subscriptions of electronic magazines are higher, and they are taking much market division right now.

\section{THE WAY BAZAAR APPLIES THE FAN ECONOMY}

Harper's BAZAAR (Chinese) has achieved remarkable success in its electronic journal, which is inseparable from the company's precise grasp of the Chinese market. To analyze this point, one has to mention the "Two-step flow of communication" theory by Elihu Katz and Pual Lazarsfeld. This communication theory extends from marketing and refers to disseminating products to audiences through so-called "opinion leaders" to achieve better advertising effects [9]. Here, the fans of the stars are obviously the audience, and BAZAAR cleverly handed over the content to the opinion leaders for a Two-step flow of communication to achieve better publicity purposes. This is an extremely important part of the fan economy in the application of this magazine. It is worth mentioning that for traditional magazines, the now rising Weibo V (users with the influence who been verified in Weibo), WeChat official account, and the self-media on other platforms will divide the audience to a certain extent. However, BAZAAR's keen sense of the digital wave makes it "turn enemies into friends": content that fans will buy with their hands, through Weibo, a social media platform with extremely fast-spreading speed, has a certain impact. Powerful self-media, such as Weibo V, make BAZAAR-related content a frequent visitor to Weibo hot searches (such as the red-carpet photos of celebrities participating in BAZAAR charity night, etc.). This is an example of an opinion leader in "Two-step flow of communication". Today, when people rarely learn about the magazine itself, these opinion leaders exert influence on the followers of the celebrity and spread BAZAAR's fan marketing to the largest possible audience. On the other hand, these contents are not just "produced by BAZAAR". These packaged contents also carry BAZAAR's unique concept: to create beautiful values, good news, and a beautiful and fashionable boutique reading platform for women (BAZAAR Chinese network). All these can make the audience of the BAZAAR fan economy aware of its representative style no matter where the "BAZAAR content" is obtained from. Therefore, the strong alliance between BAZAAR and these opinion leaders or public opinion leaders can also be called the birth of a joint commercial value.

In addition, the Weibo platform has effectively raised the economic application benefits of Harper's BAZAAR (Chinese) to a higher level. In addition to the above reasons for using opinion and opinion leaders to conduct a 
two-step flow of communication with the audience, there are also reasons for narrowing the distance between celebrities and fans. The strategy of applying the fan economy itself has a blind spot: there is a time and space distance between the product content and the audience. For fans, no matter how beautiful photos and excellent works are, the stars they like will still hang up like stars on the horizon. For BAZAAR, if they want to apply the fan economy strategy, this time and space blind zone is the key they need to overcome to hold the winning code in similar marketing. They are well versed in the uses and gratifications theory [8]. Before using the fan economy, this magazine clearly understands what fans want, and then satisfies them according to their needs: First of all, for the magazine itself, BAZAAR not only provides fans with "BAZAAR style" star photos but also attaches There is a certain level of celebrity interviews. These interviews range from work to life, and the lines between the lines can let the audience know more about their favorite stars, thereby shortening the spiritual distance. BAZAAR realized that fans would not be satisfied with this. They also opened a live broadcast room on Weibo, regularly inviting different stars to interact with fans in the live broadcast room. Thanks to advanced modern technology, live broadcasts enable celebrities and fans to interact in realtime. To ensure their brand value, celebrities rarely choose to interact with fans directly, such as live broadcasts. However, as a platform, BAZAAR can provide such an opportunity, coupled with the magazine's content, which undoubtedly shortens the space-time distance between celebrities and fans in many ways. BAZAAR is undoubtedly announcing that this unique experience tailored for fans is the only one. The cooperation from many parties and the precise mastery of use and satisfaction have also made the fan economic application of this magazine more mature.

\section{THE ACHIEVEMENTS OF THE FAN ECONOMY TO HARPER'S BAZAAR}

Although the audience of BAZAAR star electronic magazine is limited to a relatively small scale, its benefits are considerable. This is precisely because BAZAAR uses the connection between followers and followers to generate income, which Patryk Galuszka calls the "new economy of fandom". This economic model is greatly biased towards the preferences of the audience [10]. It can be said that the industry is willing to research and create things that meet the audience's preferences and then put them into practice to achieve profitability. As followers of celebrities, fans are naturally willing to pay for celebrity-related content. BAZAAR's celebrity e-magazine aimed at this point, choosing the most discussed celebrities as the topic of the current e-magazine: taking photos for it, writing interviews, and inserting interactive voices to attract fans to consume.
BAZAAR's star electronic magazine implements the strategy of "small profits but more sells" in sales, with a unit price of only 6 yuan. Still, one account can subscribe to multiple copies, and then use the number of subscriptions to further stimulate fans' desire to consume. According to statistics from douban.com, as of April 2021, the number one sales volume of a single e-magazine in China is the one with 1.285 million sales. It comes from the BAZAAR star e-magazine's Zhan Xiao \& Yibo Wang theme "Do Not Ask Origin, Just Ask Where To Go." The number one account has subscribed to 135,034 books in this subscription ranking, and even the rank one-hundredth account has subscribed to 264 books [11]. In other star e-magazines subscription ranking lists, many accounts have repeated subscriptions. It can be seen that most of the fans will choose to repeat consumption in the star e-magazine, which also greatly helped the BAZAAR e-magazine's fan economy. And this kind of repeated purchase has caused a gap between the sales of celebritythemed e-magazines and other e-magazines such as art and fashion (the subscription of non-star-themed publications often does not exceed 50,000). The top ten sales of BAZAAR electronic magazines are all based on stars as the theme. Even the tenth single e-magazine has sales of 229,000 [11]. In addition, from a quantitative point of view, the star category has the most electronic magazine (as of May 2021). There are 51 electronic magazines in the star category, 1 in the beauty category, 2 in the art category, and 3 in the fashion category. The emphasis of the electronic magazine BAZAAR can be seen.

Harper's BAZAAR continuously stimulates fans to pay for these contents by producing content that fans love, and the results have already been reflected. The sales volume of hundreds of thousands or even one million is enough to prove that despite the small size of the fan group, the willingness to consume is high enough to support the further development of the BAZAAR electronic magazine.

\section{CONCLUSION}

All in all, as a mature magazine, Harper's BAZAAR (Chinese) has maintained its good fashion image for many years. When the United States BAZAAR entered the Chinese mainland, BAZAAR quickly adjusts its marketing methods to integrate into the Chinese mainland market environment. BAZAAR is making these changes to improve its survival probability in the mainland market. After seeing the booming future of electronic magazines in the Chinese mainland market, Harper's BAZAAR (Chinese) created the main electronic edition named miniBAZAAR and created a brand-new BAZAAR star electronic magazine. These two different electronic magazines held most of BAZAAR's sales. They attract different groups of audiences purchasing Harper's BAZAAR's (Chinese) magazine. BAZAAR star e-magazine not only expanded the audience of Harper's 
BAZAAR (Chinese), more importantly, brought more benefits to BAZAAR. Thanks to Harper's BAZAAR's (Chinese) flexible use of the fan economy. In BAZAAR star e-magazines, Harper's BAZAAR (Chinese) brings in different celebrity artists to attract their respective fans. In such e-magazines, it is precise because fans' demands are as satisfied as possible, the magazine's subscriptions are positively promoted. The electronic version of BAZAAR's magazines as a path of Harper's BAZAAR (Chinese) exploring a new development is undoubtedly successful. Even though the e-magazines can attract more readers, Harper's BAZAAR (Chinese) is still actively listening to the feedback from the market. It puts forward more possibilities in the future development of e-magazines. Although we do not know what the future of BAZAAR's e-magazines will look like, it is still foreseeable that e-magazines will thrive into the future of Harper's BAZAAR (Chinese).

\section{REFERENCES}

[1] Harper's BAZAAR -TRENDS BRAND - Fashion. (n.d.). http://www.trendsgroup.com.cn/bazaar/.

[2] Nouns explain I attention economy, fan economy, net red economy, platform economy, community economy, sharing economy, sharing economy. zhihu. (n.d.). https://zhuanlan.zhihu.com/p/248750231.

[3] 2020 China Fan Economic Market Status Analysis Report - Market Status Survey and Investment Strategy Research. Chinabaogao. (2020, July 21). http://baogao.chinabaogao.com/wentiyule/506071506071.html.

[4] pengxx01. (2019, October 28). Dialogue Harper's BAZAAR: What an experience it is to create a "star electronic magazine". Tencent. https://new.qq.com/omn/20191028/20191028A060 EN00.html.

[5] Tom. (2019, November 4). Harper's BAZAAR pioneered the immersive, experiential interactive electronic magazine. TOM NEWS. https://news.tom.com/201911/4562954013.html.

[6] Guo, M. (2020, May 20). Killing red-eyed star electronic magazine: artist wool bald, fan leeks cut away. huxiu. https://www.huxiu.com/article/357944.html.

[7] The theory and study of framentation of mass audience. Docin. (2012, November 27). https://www.docin.com/p-538290675.html.

[8] Ruggiero, Thomas E. (2000) Uses and Gratifications Theory in the 21st Century, Mass Communication and Society, 3:1, 3-37, DOI: 10.1207/S15327825MCS0301_02
[9] Katz, E., \& Lazarsfeld, P.F. (2006). Personal Influence: The Part Played by People in the Flow of Mass Communications (1st ed.). Routledge. https://doi.org/10.4324/9781315126234

[10] Galuszka, P. (2015). New Economy of Fandom. Popular Music \& Society, 38(1), 25-43. https://doiorg.proxy.libraries.rutgers.edu/10.1080/03007766.2014.974325

[11] Electronic Magazine sales statistics (million/single top ten/male and female top ten). https://www.douban.com/group/topic/209959582/ 